\title{
THE ADVANTAGE OF INSTALLING HELIX CONFINEMENT IN OVER REINFORCED HSC BEAMS
}

\author{
Nuri Mohamed Elbasha \\ $7^{\text {th }}$ of April University, Faculty of Engineering (Regdalien), Libya \\ Mobile Phone: 00218927462391, Email: elbashaaustralia@yahoo.com.au
}

\begin{abstract}
The ductility of over reinforced HSC beams is enhanced through the application of helical reinforcement located in the compression region. The pitch of helix is an important parameter controlling the level of strength and ductility enhancement. This paper presents an experimental investigation of the effect of helices on the behavior of over reinforced high strength concrete beams through testing ten helically confined full scale beams. The helix pitches were 25, 50, 75, 100 and $160 \mathrm{~mm}$. Beams' cross section was $200 \times 300 \mathrm{~mm}$, and with a length of $4 \mathrm{~m}$ and a clear span of $3.6 \mathrm{~m}$ subjected to four point loading. The main results indicate that helix effectiveness is negligible when the helical pitch is $160 \mathrm{~mm}$ (helix diameter), the concrete cover spalling off load increases linearly as the helical pitch increases and the proof that the helical confinement in the compression zone of HSC beam is economical.

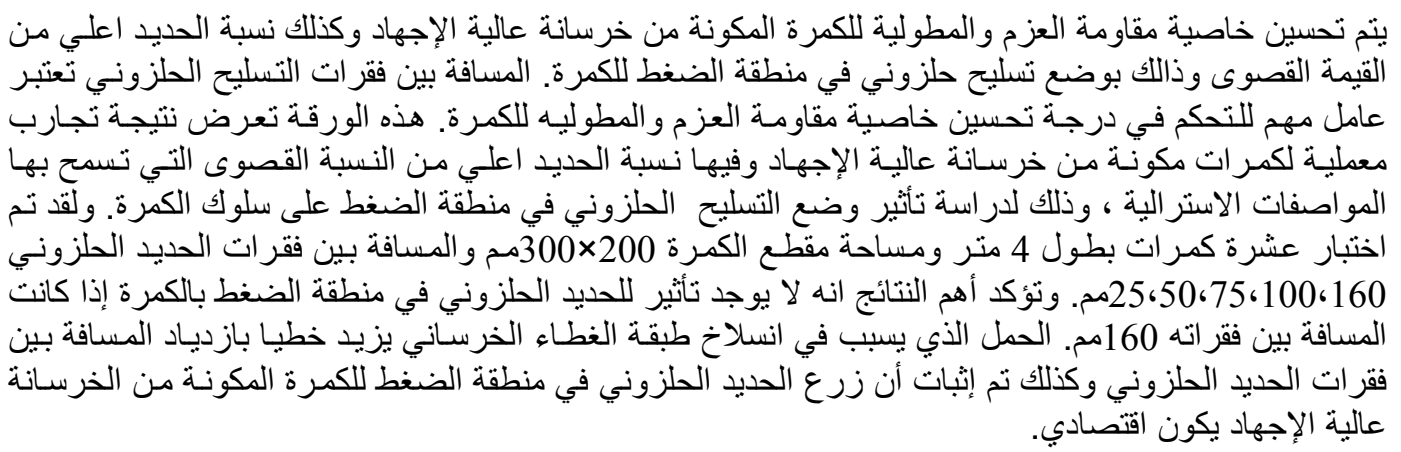

Keywords: High strength, RC beams, Over reinforcement, Confinement, Ductility

\section{INTRODUCTION}

The development of the construction industry has led to the continual improvement of construction materials. Where, high strength concrete of $100 \mathrm{MPa}$ compressive strength and reinforcement of $500 \mathrm{MPa}$ yield strength are used in beams and other construction elements. High strength concrete (HSC) could be used when the reduction in cross section of the member is required. The disadvantage of using HSC in over reinforced column or beam is its less ductile modes of failure than normal strength concrete. One option for changing the type of failure from brittle to ductile is through confining the compression region of the concrete. Helical reinforcement can be used to achieve the required ductility. It is generally accepted that helical confinement is more effective than the rectangular ties in increasing the strength and ductility of confined concrete. Helical reinforcement is effective for concrete under compression to increase the ductility as well as the compressive strength by resisting the lateral expansion due to Poisson's effect upon loading. Herein the helical reinforcement is used in the compression zone of the beams. The effectiveness of the helical confinement depends on different important variables such as helical pitch and diameter of helix.

This paper presents the benefits of installing helix confinement in over reinforced HSC beams supported by experimental results of testing ten fullscale beams with $4000 \mathrm{~mm}$ length and a cross section of $200 \mathrm{~mm}$ in width and $300 \mathrm{~mm}$ in depth.

\section{EFFICIENCY COMPARISON}

Brittle failures (compression failures) could be prevented when the beam is designed as an under reinforced section as recommended by the code of practice. However providing longitudinal reinforcement ratio over than the maximum longitudinal reinforcement ratio enhances the flexure capacity of the beam but with brittle failure (non ductile failure), which is not allowed by the code provision because ductility is an important factor 
related to human safety. There are different ways for improving ductility of concrete in compression such as providing longitudinal compression reinforcement, by using randomly oriented steel fibers, or by installing helical or tie confinement in the compression zone. Comparison between those different ways to find the most effective way is presented below. Shah et al. (1970) tested 24 groups of beams for comparison of ductility. The test was designed to be under four point loading to ensure failure in the central constant moment zone. This central zone contained closed stirrups of varying volumes, steel fibers of different amounts or compression longitudinal reinforcement of different volumes. The test results showed that the ductility of beam confined using tie confinement was 10 times the ductility of the control beams (without any ductility reinforcement), while the fibers increases ductility 4.5 times and compression steel increases ductility twice of the control beams. This result shows that the tie confinement is more effective than the compression longitudinal reinforcement and steel fiber for enhancing the ductility. Also the beams, which have longitudinal compression reinforcement, suffer from early failure because of the compression reinforcing buckling problem. However, it is well known that the confinement by helix is generally much more effective than that of rectangular or square ties. Hatanaka and Tanigawa (1992) stated that the lateral pressure produced by a rectangular tie is about 30 to 50 percent of the pressure introduced by a helix. That will be the case for compression concrete in columns or beams. However, helix confines the concrete more effectively than rectangular ties because; helix applies a uniform radial stress to the concrete along the concrete member, whereas a rectangular tends to confine the concrete mainly at the corners. Also the effective area between the ties is reduced, thus using helical confinement in the compression zone of rectangular beams is more effective than rectangular ties. There is a need for extensive experimental research to understand and provide experimental evidences about the benefit and the effectiveness of providing helix confinement in over reinforced HSC beams. The following experimental program forms part of an intensive experimental research program at the University of Wollongong.

\section{EXPERIMENTAL PROGRAM}

The aim of the experimental program in this study is to investigate the behaviour of over reinforced HSC helically confined beams. In the test program reported herein, a total of ten beams were cast in two batches each batch had five different helical pitches, namely $25,50,75,100$ and $160 \mathrm{~mm}$. The difference between the two batches was the helix bar diameter. All ten beams had the same dimensions; generic details of the beams are shown in Figure 1. Each of the beams was reinforced with $4 \mathrm{~N} 32$ bars $(32 \mathrm{~mm}$ deformed bars of $500 \mathrm{MPa}$ tensile strength and of normal ductility). Stirrups of plain $10 \mathrm{~mm}$ diameter (250 MPa tensile strength) were provided at either third end of the beams at a spacing of $80 \mathrm{~mm}$. Two $10 \mathrm{~mm}$ bars were installed at the top of the beams at either third in order to keep the ties in-place. For the first five beams the helix was made of $12 \mathrm{~mm}$ plain bars and for the second five beams the helix was made of $8 \mathrm{~mm}$ plain bars. Each group of five beams were cast at the same day using five wooden moulds. The beams were then cured by covering them with wet Hessian bags.

The helical reinforcement was plain bar with diameter 8 and $12 \mathrm{~mm}$ with $500 \mathrm{MPa}$ yield strength. Each beam had four longitudinal deformed steel bars, the diameter was $32 \mathrm{~mm}$ and the yield strength was $500 \mathrm{MPa}$. The concrete used in this experimental program was supplied as ready mix by a local supplier and was specified to gain $100 \mathrm{MPa}$ for both batches. The concrete compressive strength of the first five beams was $105 \mathrm{MPa}$, and the concrete compressive strength of the second five beams was $80 \mathrm{MPa}$.

All beams were heavily instrumented. Reinforcement steel deformation was measured using electrical - resistance strain gauges (10 mm long) glued to the steel bars at mid-span of the bar and 300 $\mathrm{mm}$ away from the mid-span in both sides of the bar. Also the strains of the helical reinforcement were measured using electrical - resistance strain gauges (5 mm long) glued at the bottom, top and sides of the helical reinforcement at the mid-span of the beam and $300 \mathrm{~mm}$ away from the mid-span of the beam. The strain on the compression zone of the beam was measured using two electrical - resistance strain gauges (60 mm long) glued on the top surface at midspan of the beam. For each beam, two embedment gauges were placed at a depth of $40 \mathrm{~mm}$, one at the beam's mid-span and the other 300 away from the mid-span of the beam. The data recorded from the embedment gauges were used to calculate the strains at the top surface after spalling off the concrete cover.

\section{ANALYSIS OF TEST RESULTS}

A summary of the test results is presented in Table 1. Observed load versus mid-span deflection only are presented in this paper and discussed in the following sections.

From Figures 2 and 3, it could be noted the remarkable effect of helical pitch on mid-span deflection. Beams, which have helical pitches of 25 , 50,75 and $100 \mathrm{~mm}$ failed in a ductile manner. The level of the ductility depends on helical pitch. 
The Beam 12HP160 failed in a brittle mode, as the upper concrete in the compression zone was crushed and the maximum load was $413 \mathrm{kN}$ and then dropped to $150 \mathrm{kN}$. Also the maximum load for Beam 8HP160 was $376 \mathrm{kN}$ and then dropped to 94 $\mathrm{kN}$. This drop indicates the effect of confinement is negligible when the spacing is equal to the confinement diameter, which is in agreement with the experimental results by Iyengar et al. (1970) and Martinez et al. (1984). Beams 12HP25 and 8HP25 have a maximum deflection of 240 and $185 \mathrm{~mm}$, respectively and the deflection is reduced as the pitch is increased. Figure 4 shows the concrete cover spalling off and Figure 5 shows the ultimate deflection for beam 12HP25.

Current design provisions of ACI 318R-02 (2002) and AS 3600 (2001) do not allow the design of over reinforced concrete beams due to lack of ductility of such beams. However, this research provides experimental proof that installing helix with suitable pitch and diameter in the compression zone of beams enhances their ductility significantly. Thus, designers could use high-strength concrete and high-strength steel to design over reinforced beams confidently, hence taking the full advantage of these high strength materials by utilizing their full potential.

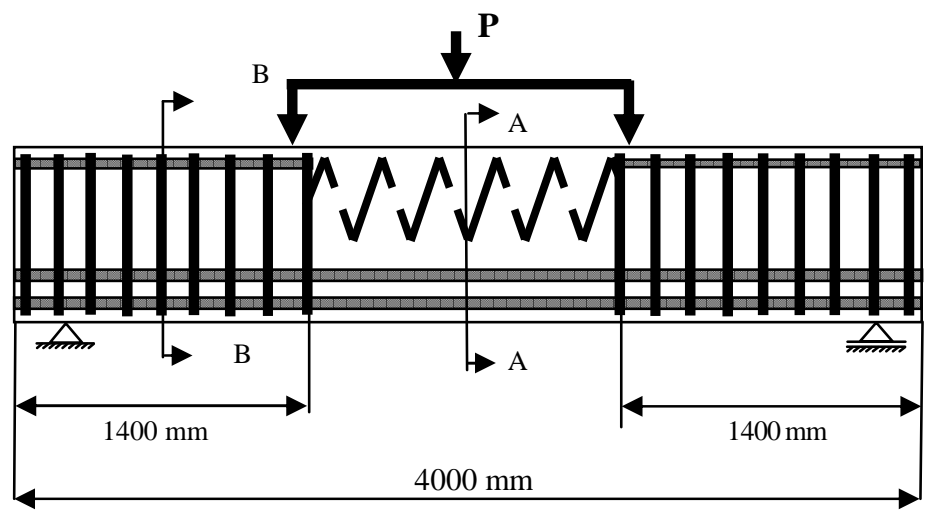

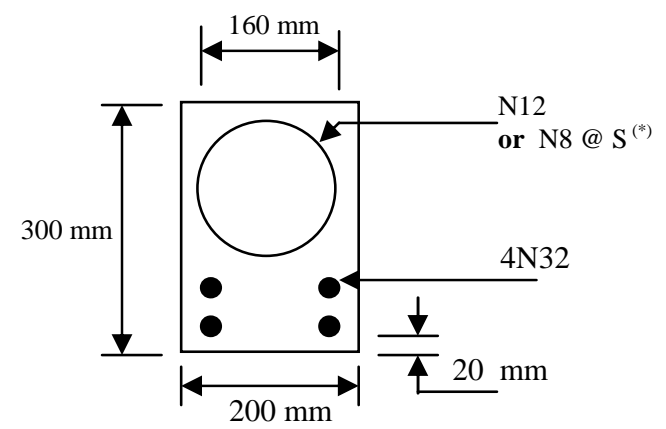

$\mathrm{S}^{(*)}=25,50,75,100$ and $160 \mathrm{~mm}$

SECTION A-A

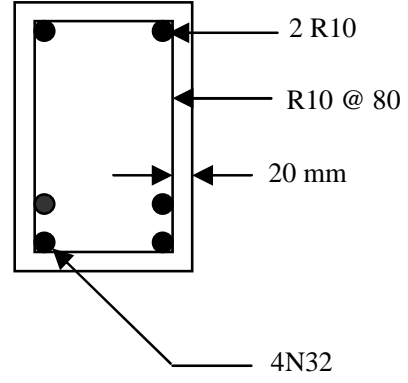

SECTION B-B

Fig. 1 Loading configuration and specimen details
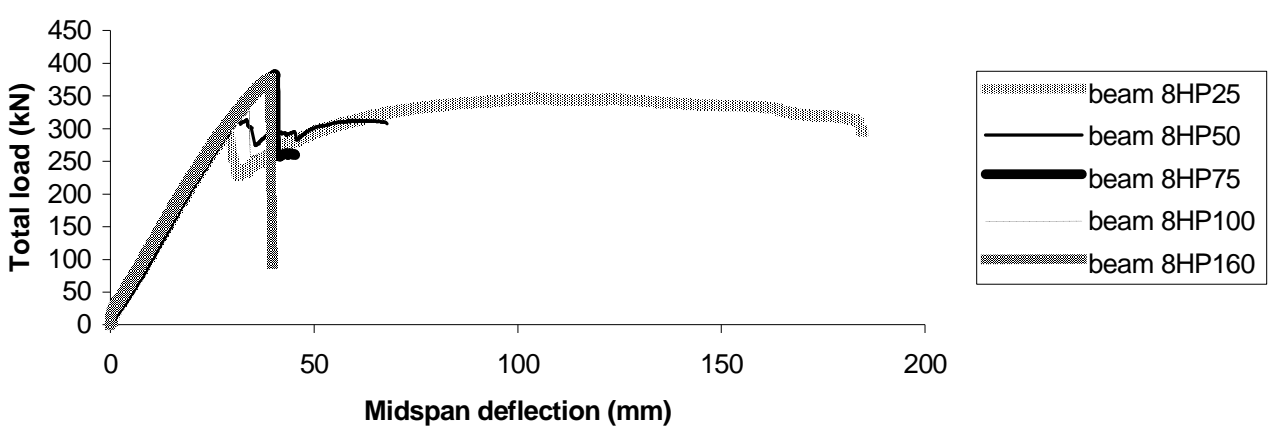

Fig. 2 Load-deflection curves for beams with helix diameter $8 \mathrm{~mm}$ 


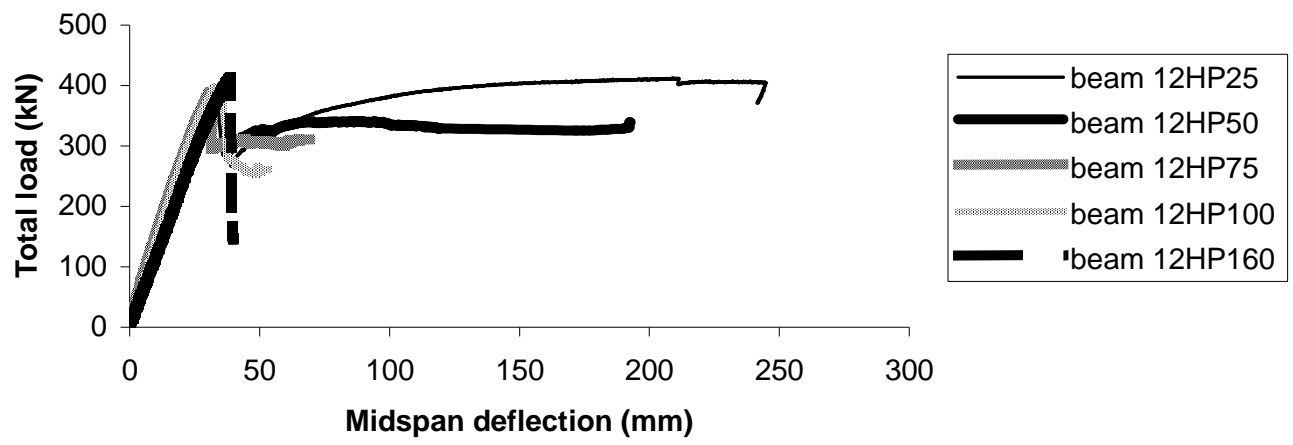

Fig. 3 Load-deflection curves for beams with helix diameter $12 \mathrm{~mm}$

I'able 1 Summary of beam results

\begin{tabular}{cccccccc}
\hline $\begin{array}{c}\text { Beam } \\
\text { specimen }\end{array}$ & $\begin{array}{c}\text { helical } \\
\text { reinforcement } \\
\text { ratio }\end{array}$ & $\begin{array}{c}\text { Concrete } \\
\text { compressive } \\
\text { strength, } \\
\text { MPa }\end{array}$ & $\begin{array}{c}\text { Load at } \\
\text { cover } \\
\text { spalling } \\
\text { off, } \mathbf{k N}\end{array}$ & $\begin{array}{c}\text { Failure } \\
\text { load, } \\
\mathbf{k N}\end{array}$ & $\begin{array}{c}\text { Yield } \\
\text { deflection } \\
\mathbf{\Delta}_{\mathbf{y}}, \mathbf{m m}\end{array}$ & $\begin{array}{c}\text { Ultimate } \\
\text { deflection } \\
\mathbf{\Delta}_{\mathbf{u}}, \mathbf{m m}\end{array}$ & $\begin{array}{c}\text { Displaceme } \\
\text { nt ductility } \\
\text { index } \\
\boldsymbol{\Delta}_{\mathbf{u}} / \boldsymbol{\Delta}_{\mathbf{y}}\end{array}$ \\
\hline 12HP25 & 0.113 & 100 & 372 & 411 & 40 & 240 & 6 \\
8HP25 & 0.050 & 80 & 297 & 346 & 32 & 185 & 5.7 \\
12HP50 & 0.057 & 100 & 386 & 340 & 35 & 193 & 4.6 \\
8HP50 & 0.025 & 80 & 324 & 310 & 31 & 68 & 2.2 \\
12HP75 & 0.038 & 100 & 388 & 310 & 32 & 65 & 2 \\
8HP75 & 0.017 & 80 & 381 & 300 & 40 & 45 & 1.1 \\
12HP100 & 0.028 & 100 & 398 & 260 & 33 & 52 & 1.6 \\
8HP100 & 0.013 & 80 & 326 & 250 & 34 & 41 & 1.2 \\
12HP160 & 0.018 & 100 & 413 & $150^{*}$ & 38 & 38 & 1 \\
8HP160 & 0.008 & 80 & 376 & $94^{*}$ & 39 & 39 & 1 \\
\hline
\end{tabular}

*the load dropped suddenly

Although the experimental program of this study has proven that the helices confinement provided in the compression zone of over reinforced HSC beam have improved the ductility, the progression of this concept into the engineering industry needs to be considered. For a particular cross section, there is a limit of longitudinal reinforcement ratio according to the code. However it could install more longitudinal reinforcement ratio if the flexure strength required is more than the flexure strength of this particular section, that it may change the section from under reinforced to over reinforced and then could solve the problem of the brittle failure by confining the compression zone with helix confinement with suitable helical pitch according to the level of ductility required. The strength gain is calculated by comparing the tested over reinforced helically confined beams with under reinforced beams (theoretical). The tested and theoretical beams have the same cross-section $(200 \times 300 \mathrm{~mm})$ and concrete compressive strength. The theoretical reinforced beams have been designed as an under reinforced section (longitudinal reinforcement ratio is slightly less than maximum longitudinal reinforcement ratio allowed according to ACI 318R-02 (2002)).
Table 2 shows the comparison between the moment capacity of the helically confined beams with the moment capacity of the theoretical HSC beam without helix. It is noted that the ratio between the experimental moments with the theoretical moments was significantly high. The strength of over reinforced HSC helically confined beam was 1.3 times (average of the seven beams only, because beam 8HP75 was considered as experimental error) of the theoretical results of under reinforced HSC beam (the longitudinal reinforcement ratio is slightly less than the maximum longitudinal reinforcement ratio allowed by ACI 318R-02 (2002)). As a result of the comparison, Table 2 shows the most important issue is the gain of the strength with significant improvement in ductility. Experimental results show considerable displacement ductility index for beams confined with helical pitch 25 and $50 \mathrm{~mm}$. That results promote the use over reinforced beams in a structure safely by adding helix confinement in the compression zone. In different sophisticated structures such as nuclear reactors, high-rise building and bridges beam is economical to increase longitudinal reinforcement ratio more than the maximum longitudinal reinforcement ratio allowed 
Nuri Mohamed Elbasha, "The Advantage Of Installing Helix Confinement In Over Reinforced Hsc Beams"

by the design code and then the ductility can be improved effectively by confining the compression zone using helix confinement. In other words when the cross section of the beam is restricted and the beam strength required is more than the strength of the beam if designed as an under reinforced section (the longitudinal reinforcement ratio is less than the maximum longitudinal reinforcement ratio allowed by the code), then it could enhance the strength up to the required strength by increasing the longitudinal reinforcement ratio and enhancing the ductility by confining the compression zone using the helical confinement with proper pitches.

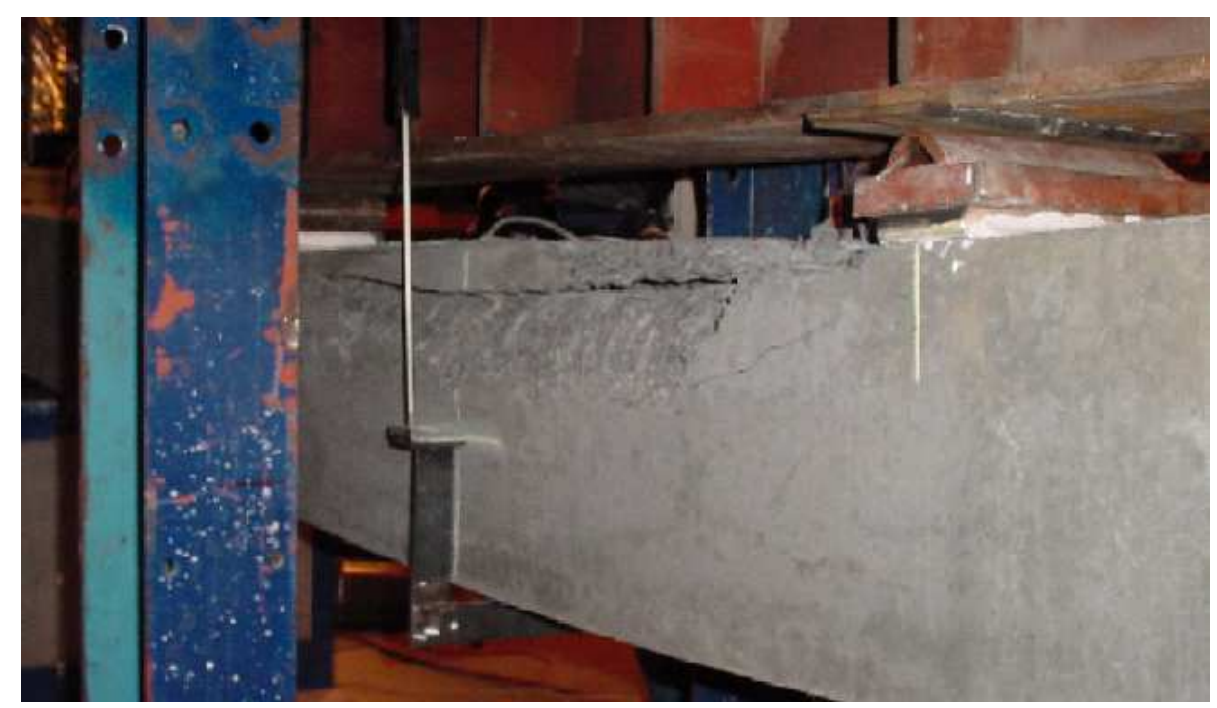

Fig. 4 Concrete cover spalling off for beam $12 \mathrm{HP} 25$

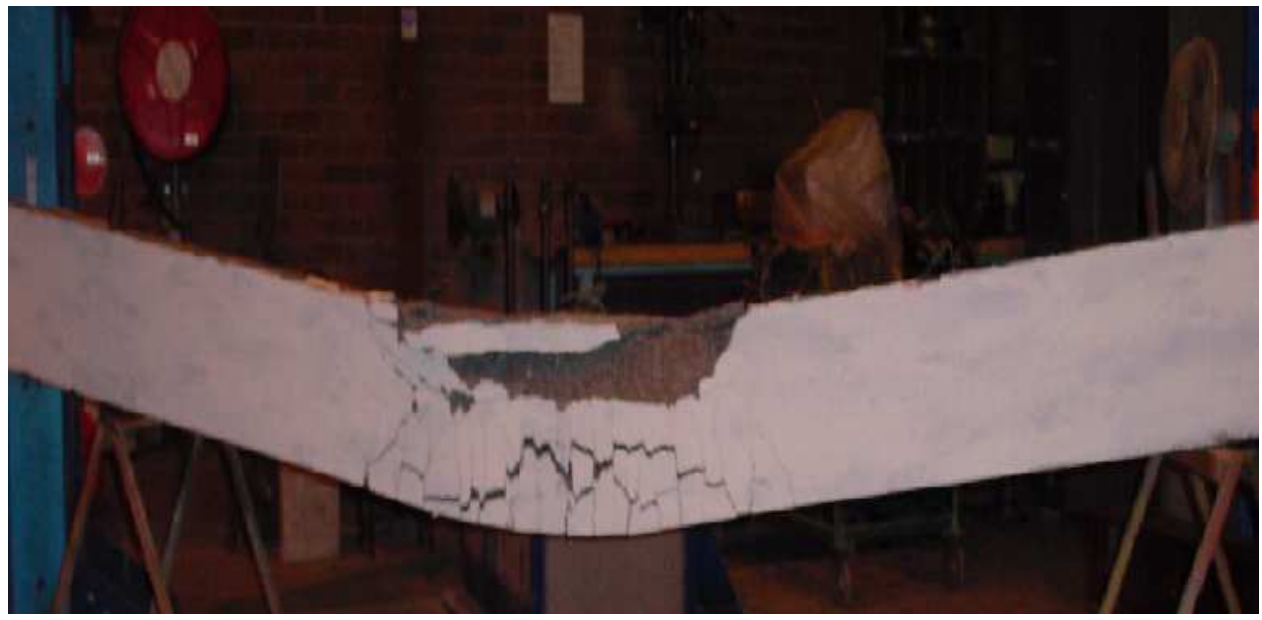

Fig. 5 Ultimate deflection for beam 12HP25

Table 2 Comparison between experimental and theoretical moment capacity

\begin{tabular}{ccccc}
\hline $\begin{array}{c}\text { Beam } \\
\text { specimen }\end{array}$ & $\left(\boldsymbol{\rho} / \boldsymbol{\rho}_{\max }\right)$ & $\begin{array}{c}\text { Experimental moment capacity at } \\
\text { cover spalling off, } \mathbf{M}_{\mathbf{e x p}}(\mathbf{k N . m})\end{array}$ & $\begin{array}{c}\text { Theoretical moment capacity } \\
\mathbf{w h e n}\left(\boldsymbol{\rho} \cong \boldsymbol{\rho}_{\max }\right), \mathbf{M}_{\text {the }}(\mathbf{k N . m})\end{array}$ & $\mathbf{M}_{\mathbf{e x p}} / \mathbf{M}_{\text {the }}$ \\
\hline 12HP25 & 1.45 & 223.2 & 177 & 1.26 \\
8HP25 & 1.94 & 178.2 & 149 & 1.20 \\
12HP50 & 1.45 & 231.6 & 177 & 1.31 \\
8HP50 & 1.94 & 194.4 & 149 & 1.30 \\
12HP75 & 1.45 & 232.8 & 177 & 1.32 \\
8HP75 & 1.94 & 228.6 & 149 & 1.53 \\
12HP100 & 1.45 & 238.8 & 177 & 1.35 \\
8HP100 & 1.94 & 195.6 & 149 & 1.31 \\
\hline
\end{tabular}


The most economical advantages when the helical confinement is provided in the compression zone come through reducing the beam size and still gaining the required flexural strength with acceptable ductility. Reducing the size of the beam is reducing the formwork, which means saving construction time, material and labour. This saving of money is fixed amount at the time of the construction, for example could save $\$ \mathrm{x}$ only as a result of reducing construction time, material and labour for multistorey buildings. However reducing the size of the beam is providing more space on each storey of the building the amount of space saved could use in an extra storey at the building, which increases the efficiency of the structure. The extra rent from extra storey and the rent are increased by time. In addition, the price of the land and the structure as a whole are increased with the time. This indicates the amount of money saved regarding the space. It is a cumulative amount that is more valuable than the money saved regarding saving construction time, material and labour (fixed amount). For the same example if the spacing could save $(\$ x / 2)$ only the half of the amount saved by construction time, material and labour, but $\$ \mathrm{x} / 2$ will be yearly. Then after 30 years could save $\$ 15 \mathrm{x}$ which is 15 times the amount of saving regarding saving construction time, material and labour (fixed amount).

\section{CONCLUSIONS}

The experimental program in this study is to investigate and provide experimental evidence about the significant effect of helical confinement on the displacement ductility of helically confined HSC beam. Ten over reinforced HSC beams helically confined were tested. Conclusions can be drawn about the behaviour of these beams with different helical pitch of 25,50,75, 100 and $160 \mathrm{~mm}$ and different helix diameter 8 and $12 \mathrm{~mm}$.

The two beams with helical pitch of $160 \mathrm{~mm}$ (equal to the core diameter of the beam) have shown to be very brittle in their failure, providing no plateau region in their load deflection curves. The concrete spalled off at the failure load. The conclusion drawn from testing these beams is that the confinement effect is negligible when the helical pitch is equal to or greater than the core diameter for helically confined beams.

The other beams with helical pitch of 25, 50, 75 and $100 \mathrm{~mm}$ have shown to be ductile and the level of ductility is based on the helical pitch. The helices effectively confined the compressive region when the helical pitch was reduced. It is interesting to note that the displacement ductility index increases as the helical pitch decreases. In other words, displacement ductility index is inversely proportional with the helical pitch.
The effect of helix diameter is negligible when the helix pitch is very small such as $25 \mathrm{~mm}$ also when the helix pitch is as large as 75 or $100 \mathrm{~mm}$. However the significant effect of the helix diameter on the displacement ductility index is only when the helix pitch is between $25 \mathrm{~mm}$ and $75 \mathrm{~mm}$.

There was no significant difference between the yield deflections of the beams but there was significant difference between the ultimate deflections for the ten beams. That is an indicator that the helix effectiveness takes place after yield deflections take place and then the concrete strength is enhanced (confined concrete strength). The change of confined concrete strength depends on many factors such as helix pitch and helix diameter. As a result, the failure type changes from brittle to ductile.

The strength of the helically confined beam was enhanced by 1.3 times of the beam designed theoretically as under reinforced beam (the longitudinal reinforcement ratio is slightly less than the maximum longitudinal reinforcement ratio allowed by ACI 318R-02 (2002)). Also the ductility of over reinforced HSC beam is enhanced significantly by providing helical confinement in the compression zone.

It could be concluded that the helical confinement in the compression zone of HSC beam is economical because it reduces the beam size which means saving construction time, material, labour and space.

Generally, providing the helix in the compression zone of beams with a suitable helix pitch is the most economical and effective way to enhance the strength and ductility of over reinforced HSC beams reinforced with high strength steel.

\section{REFERENCES}

[1] ACI 318-02, 2002, "Building code Requirements for Structural Concrete", American Concrete Institute, Michigan, USA.

[2] AS3600, 2001, "Australian Standard for Concrete Structures", Standards Association of Australia. North Sydney, Australia.

[3] Hatanaka, S. and Tanigawa, Y., 1992, "Lateral Pressure Requirements for Compressive Concrete", Proceedings of $10^{\text {th }}$ World Conference on Earthquake Engineering, Madrid, 2603-2608.

[4] Iyengar, K.T.; Sundra, R.; Desayi, P. and Reddy, K.N., 1970, "Stress-Strain Characteristics of Concrete Confined in Steel Binders", Magazine of Concrete Research 22(72):173-184.

[5] Martinez, S., Nilson, A. H. and Slate, F.O., 1984, "Spirally Reinforced High-Strength Concrete Columns", ACI Structural Journal, Michigan, USA 81(5):431-442.

[6] Shah, S.P., and Rangan, B.V., "Effects of Reinforcements on Ductility of Concrete", Journal of The Structural Division 1970;96,ST6:1167-1184. 